\title{
Impact of Vitamin D Deficiency on Systemic Inflammatory Markers and Left Ventricular Functions in Rachitic Infants
}

\author{
Azza S. Abedelhaffez ${ }^{1}$ and Kotb A. Metwalley ${ }^{2}$ \\ Medical Physiology and Paediatric ${ }^{2}$ Departments, \\ Faculty of Medicine, Assiut University, Egypt
}

\begin{abstract}
Background: Circulating 25 hydroxyvitamin D (25 (OH)D), an accurate measure of vitamin $D$ status, is markedly reduced in rachitic infants. Aside from the known relationship between vitamin $D$ and bone, vitamin $D$ has also been implicated in cardiovascular homeostasis, immune function and inflammation. Furthermore, a mass of evidence is accumulating that vitamin $D$ deficiency could lead to cardiovascular complications and imbalance of cytokines profile. Our objective was to study the relationship between vitamin $D$ status (as determined by serum25(OH) D concentrations) and inflammatory markers and left ventricular function in rachitic infants, also to evaluate the effect of vitamin $D$ supplementation on the above parameters. Subjects and methods: This study included two groups; vitamin D deficiency rickets (VDDR) group (25 infants) and an age matched control group (15 infants). After subsiding of the acute illness, the rachitic infants received vitamin $D$ supplementation for 6 months. Blood samples were collected in the morning before the start of treatment and analyzed for serum $25(\mathrm{OH}) \mathrm{D}$, intact parathyroid hormone (iPTH), Alkaline phosphatase (ALP), calcium (Ca), Phosphorus (Ph) and inflammatory markers [interleukin-6 (IL-6), and C-reactive protein (CRP)]. Electrocardiogram (ECG) and echocardiography measuring left ventricular functions were done. The biochemical variables, ECG and echocardiography were assessed at baseline and after 6 months of vitamin D supplementation. Results: VDDR group had significant lower 25(OH)D, Ca, Ph and significant higher iPTH, ALP, IL-6 and CRP compared to the age matched control group at baseline. Echocardiographic finding revealed significant increase in LVEDD and LVESD and significant decrease in EF\% and FS\% in VDDR group compared to the age matched control group at the study entry. Also, ECG finding showed abnormality in some patients at baseline. The biochemical, echocardiographic and ECG variables improved significantly after 6 months of vitamin $D$ supplementation and reached to those levels found in the age matched control group. Finally, we found negative correlations between $25(\mathrm{OH}) \mathrm{D}$ level and IL-6, CRP, LVEDD and LVESD. Also, positive correlations were found between $25(\mathrm{OH}) D$ and EF\% and FS\%. These correlations were observed at baseline and after 6 months of vitamin D treatment. Conclusion: VDDR is associated with increased inflammatory markers and impairment of left ventricular functions in rachitic infants. Vitamin D supplementation ameliorated these effects. Also, results gleaned from this investigation support the possible contributing role of the elevated inflammatory markers in the pathophysiology of left ventricular impairment in vitamin $D$ deficiency rachitic infants. More studies are needed to fully characterize the relationship between Vitamin $D$ induced inflammation and cardiac function in rachitic infants.
\end{abstract}


Key words: Vitamin D deficiency rickets, infants, inflammatory markers, left ventricle function.

\section{INTRODUCTION}

Nutritional rickets is a disease resulting from impaired bone mineralization due to insufficient calcium or phosphorus in growing children. It ranks as one of the five commonest diseases in children from developing countries and is still quite common in the Middle East ${ }^{(1)}$. It is thought to be secondary to vitamin D deficiency ${ }^{(2)}$.

Several studies have shown that vitamin D may play a role in many biochemical mechanisms in addition to bone and calcium metabolism. Recently, vitamin D has sparked widespread interest because of its involvement in the homeostasis of the cardiovascular system $^{(3)}$. There is growing evidence that vitamin D either directly or indirectly affects cardiac structure and function ${ }^{(4)}$. The vitamin D receptor knockout mouse model demonstrates marked cardiomyocyte hypertrophy and increased left ventricular weight ${ }^{(5)}$, and $\quad 1,25(\mathrm{OH})_{2} \mathrm{D}_{3} \quad$ attenuates cardiomyocyte proliferation ${ }^{(6)}$ and hypertrophy $^{(7)}$ in vitro. In human, Vitamin D deficiency has been shown to be associated with an increased incidence of left ventricular hypertrophy and congestive heart failure ${ }^{(8)}$. Although it has been reported that asymptomatic left ventricular dysfunction may develop in infants with vitamin D deficiency rickets (VDDR) and it improves with treatment, dilated cardiomyopathy and congestive heart failure are rare ${ }^{(9)}$.
There is increasing evidences that low vitamin D status may lead to immune dysregulation. Studies have shown defective macrophage function, such as impaired chemotaxis, phagocytosis, and increased production of proinflammatory cytokines in vitamin D deficiency ${ }^{(\mathbf{1 0})}$. Vitamin D supplementation improved cytokines profiles in animals ${ }^{(11)}$, patients with congestive heart failure ${ }^{(\mathbf{1 2})}$ and human coronary arterial endothelial cells ${ }^{(13)}$.

To date there is little evidence on the associations of $25(\mathrm{OH}) \mathrm{D}$ with indicators of inflammation and cardiac functions in rachitic infants. So, the aim of this work was to evaluate the effect of vitamin D deficiency on the inflammatory markers; interlukin-6 (IL-6) and C-reactive protein (CRP) and the left ventricular function in the rachitic infants. Also, we examined the effect of vitamin D supplementation on the above mentioned parameters. Moreover, we searched for potential correlations between 25(OH)D and IL-6, CRP and selected echocardiographic parameters.

\section{MATERIALS \& METHODS}

\section{Participants}

This study included 40 infants with age range from 6 months to 2 years. 25 (14 boy and 11 girls) infants with vitamin $\mathrm{D}$ deficiency rickets (VDDR). 15 (9 boys and 6 girls) apparently healthy, age matched infants were studied as a control. Both patients and controls were recruited 
from Pediatric Outpatients Clinics and Pediatric Emergency department in Assiut University Children Hospital, Egypt.

The diagnosis of VDDR was based on a combination of clinical, radiographic and biochemical features of VDDR ${ }^{(14)}$. Exclusion criteria were previous history of heart disease or any other condition that affect cardiac functions, history of prematurity or intrauterine growth retardation, renal, liver, intestinal or central nervous system disease, family history of hereditary forms of rickets, treatment with vitamin $\mathrm{D}$, malnutrition and anemia. The work was approved by the Assiut University Ethics Scientific Committee and an informed consent from the parents of infants had been performed.

At the study entry, blood samples were taken from all patients (VDDR group) and then received intramuscular injection of vitamin D (cholecalciferol) (600 000 IU) once and oral calcium lactate for 2 weeks followed by oral maintenance dose of vitamin D 400 unit/day for 6 months.

\section{A) Biochemical analysis}

Blood samples were drawn in the morning between $8 \mathrm{AM}$ and $11 \mathrm{AM}$ at baseline and at the end of the 6 months of treatment. After centrifugation at room temperature for 20 minutes, aliquots of the serum samples were frozen consecutively and stored at $-20^{\circ} \mathrm{C}$ until analyzed.

The following biochemical parameters were measured using ELISA kits: IL-6 (AviBion Human IL-6 ELISA kit, Orgenium Laboratories, Finland), C-reactive protein (highly sensitive CRP ELISA Kit Monobind Inc., USA). 25-hydroxyvitamin D (25OHD) was measured using enzyme immunoassay (Immunodiagnostic Systems Inc., Fountain Hills, AZ) and intact parathyroid hormone (i-PTH) was measured using immunoassay (Immulite 1000, Diagnostic Products Corporation). Alkaline phosphatase was determined using Abbot Aeroset Autoanalyzer by spectrophotometric method. $\mathrm{Ca}$ and $\mathrm{Ph}$ levels were measured using routine laboratory tests.

\section{B) Electrocardiographic Measurements \\ Resting12-lead}

electrocardiograms (ECG) studies were performed for all rachitic cases and interpreted in accordance with the patient's age and sex, and the QT segment was corrected for heart rate (QTc) ${ }^{(15)}$.

\section{C) Echocardiography}

After improvement of acute illness of studied cases, for all patients and controls, left ventricle functions were evaluated by echocardiography using Vivid 3, Aloka machines with transducers of 3.5,7 MHz. We used different echocardiography Modes: 1) two dimensional (2D) to verify cardiac chambers structures and details of anatomy. 2) M mode study to estimate the other echocardiographic variables according to the criteria of the American Society of Echocardiography ${ }^{(16)}$.

\section{Statistical analysis:}

Data are expressed as mean \pm standard deviation (SD) for all parameters. The data were analyzed by using GraphPad Prism data analysis program (GraphPad Software, Inc., San Diego, CA, USA). For the comparison of statistical 
significance between cases and control, Student Newman-Keuls t-test for unpaired and paired data was used. Linear correlations were performed by Spearman's or Pearson's test. A value of $\mathrm{P} \leq 0.05$ was considered statistically significant.

\section{RESULTS}

The biochemical and echocardiographic variables of the two groups at the baseline are summarized in Table 1. patients with VDDR had significantly lower level of serum $\mathrm{Ca}, \mathrm{Ph}$ and $25(\mathrm{OH})$ vitamin $\mathrm{D}$ (for all $\mathrm{P}<0.001$ ) and significantly higher level of alkaline phosphatase, parathyroid hormone, IL-6 and CRP (for all $\mathrm{P}<0.001$ ) in comparison with age matched control group. The echocardiographic parameters of VDDR group; LVEDD and LVESD, were significantly higher (for both $\mathrm{P}<0.001$ ) while $\mathrm{EF} \%$ and $\mathrm{FS} \%$ were significantly lower (for both $\mathrm{P}<0.001$ ) when compared to the control group. No significant difference in IVSWT, LVPWT, I/L, LVM, LVMI and E/A between VDDR group and the control group.

After 6 months of treatment (shown in table 2), the serum $\mathrm{Ca}, \mathrm{Ph}$ and $25(\mathrm{OH})$ vitamin $\mathrm{D}$ of the VDDR group were significantly higher (for all $\mathrm{P}<0.001)$ compared to the levels found at the baseline. Alkaline phosphatase, parathyroid hormone, IL-6 and CRP levels of VDDR participants after 6 months of treatment were significantly lower (for all $\mathrm{P}<0.001)$ compared to levels showed at baseline. All of these parameters return to normal levels and were not significantly different when compared to an age matched control group. The echocardiographic variables; LVEDD and LVESD, were significantly lower (for both $\mathrm{P}<0.001$ ) while $\mathrm{EF} \%$ and $\mathrm{FS} \%$ were significantly higher (for both $\mathrm{P}<0.001$ ) when compared to the baseline levels. These variables were not significantly different compared to the age matched control group.

ECG of VDDR group showed T wave abnormalities in 3 cases and prolonged QT interval in 5 cases at the baseline. These changes disappeared after 6 months of vitamin D supplementation (data not shown).

\section{Correlation analysis}

Figures 1 (A\&B), 2 (A\&B) showed correlation coefficient between $25(\mathrm{OH})$ vitamin $\mathrm{D}$ level and IL-6, CRP, echocardiographic variables: LVEDD, LVESD, EF\% and FS\% among VDDR group at baseline and after 6 months of treatment. At baseline, serum $25(\mathrm{OH})$ vitamin $\mathrm{D}$ level had significant -ve correlation with IL-6 $(\mathrm{r}=-0.68$ and $\mathrm{P}<0.001)$, CRP $(\mathrm{r}=-0.59$ and $\mathrm{P}<0.01)$, LVEDD $(\mathrm{r}=$ 0.66 and $\mathrm{P}<0.001)$, LVESD $(\mathrm{r}=-0.79$ and $\mathrm{P}<0.001)$ and significant $+\mathrm{ve}$ correlation with $\mathrm{EF} \% \quad(\mathrm{r}=0.71$ and $\mathrm{P}<0.001)$ and $\mathrm{FS} \% \quad(\mathrm{r}=0.69$ and $\mathrm{P}<0.001)$. After 6 months of treatment, serum $25(\mathrm{OH})$ vitamin D level had significant -ve correlation with IL-6 $(\mathrm{r}=-0.94$ and $\mathrm{P}<0.001)$, CRP $(r=-0.53$ and $\mathrm{P}<0.01)$, LVEDD $(\mathrm{r}=-0.69$ and $\mathrm{P}<0.001)$, LVESD $(\mathrm{r}=$ 0.77 and $\mathrm{P}<0.001)$ and + ve correlation with $\mathrm{EF} \%(\mathrm{r}=0.87$ and $\mathrm{P}<0.001)$ and $\mathrm{FS} \%(\mathrm{r}=0.56$ and $\mathrm{P}<0.01)$. 
Table 1: Biochemical and echocardiographic variables of the study groups at baseline

\begin{tabular}{|l|l|l|l|}
\hline Variables & $\begin{array}{l}\text { VDDR group } \\
\text { N=25 }\end{array}$ & $\begin{array}{l}\text { Control group } \\
\mathbf{N}=\mathbf{1 5}\end{array}$ & $\mathbf{P}$ value \\
\hline Calcium (mg/dl) & $7.1 \pm 0.6$ & $9.1 \pm 0.6$ & $\mathrm{P}<0.001$ \\
\hline Phosphorus (mg/dl) & $1.8 \pm 0.6$ & $5.5 \pm 0.8$ & $\mathrm{P}<0.001$ \\
\hline ALP $(\mathrm{IU})$ & $490 \pm 50.2$ & $142 \pm 31.6$ & $\mathrm{P}<0.001$ \\
\hline iPTH (pg/ml) & $212.8 \pm 25.3$ & $44 \pm 6.6$ & $\mathrm{P}<0.001$ \\
\hline 25(OH) vitamin D (ng/ml) & $5.18 \pm 0.68$ & $24.5 \pm 1.4$ & $\mathrm{P}<0.001$ \\
\hline CRP (mg/l) & $14.01 \pm 1.73$ & $5.35 \pm 1.42$ & $\mathrm{P}<0.001$ \\
\hline IL-6 (ng/l) & $26.07 \pm 5.01$ & $6.08 \pm 1.3$ & $\mathrm{P}<0.001$ \\
\hline LVEDD (mm) & $31.92 \pm 5.01$ & $22.14 \pm 2.56$ & $\mathrm{P}<0.001$ \\
\hline LVESD (mm) & $23.57 \pm 1.15$ & $15.35 \pm 1.82$ & $\mathrm{P}<0.001$ \\
\hline EF $(\%)$ & $57.41 \pm 3.43$ & $65.36 \pm 7.86$ & $\mathrm{P}<0.001$ \\
\hline FS $(\%)$ & $23.96 \pm 0.99$ & $36.25 \pm 2.4$ & $\mathrm{P}<0.001$ \\
\hline IVSWT (mm) & $3.89 \pm 0.42$ & $4.16 \pm 0.54$ & $\mathrm{NS}$ \\
\hline LVPWT (mm) & $3.75 \pm 0.5$ & $3.82 \pm 0.5$ & $\mathrm{NS}$ \\
\hline I/L & $1.06 \pm 0.06$ & $1.04 \pm 0.04$ & $\mathrm{NS}$ \\
\hline LVM (g) & $30.77 \pm 4.2$ & $31.22 \pm 2.85$ & $\mathrm{NS}$ \\
\hline LVMI (g/m $\left.{ }^{2}\right)$ & $67.4 \pm 11.5$ & $65.83 \pm 14.5$ & $\mathrm{NS}$ \\
\hline E/A & $1.33 \pm 0.05$ & $1.35 \pm 0.08$ & $\mathrm{NS}$ \\
\hline
\end{tabular}

Quantitative variables are expressed as mean $\pm \mathrm{SD}$, student $\mathrm{t}$ test were used to compare between the two groups. ALP: alkaline phosphatase; iPTH:intact parathyroid hormone; CRP: C-reactive protein; IL-6: interlukin-6; LVEDD: Left ventricular end diastolic diameter; LVESD: left ventricular end systolic diameter; FS: fractional shortening; EF: ejection fraction; IVSWT: interventricular septal wall thickness; LVPWT: left ventricular posterior wall thickness; I/L: interventricular posterior wall thickness / left ventricular posterior wall thickness; LVM: left ventricular mass; LVMI: left ventricular mass index; E/A ratio: E wave /A wave ratio. 
Table 2: Biochemical and echocardiographic variables of the study groups at baseline, after 6 months of treatment.

\begin{tabular}{|c|c|c|c|c|c|}
\hline \multirow[t]{2}{*}{ Variable } & \multirow{2}{*}{$\begin{array}{l}\text { VDDR at } \\
\text { base line }\end{array}$} & \multirow{2}{*}{$\begin{array}{l}\text { VDDR after } \\
6 \text { month of } \\
\text { treatment }\end{array}$} & \multirow[t]{2}{*}{ Control } & \multicolumn{2}{|l|}{$P$ value } \\
\hline & & & & $\begin{array}{l}\text { At base line vs } \\
\text { after } 6 \text { months } \\
\text { of treatment }\end{array}$ & $\begin{array}{l}\text { After } 6 \\
\text { months vs } \\
\text { control }\end{array}$ \\
\hline Calcium (mg/dl) & $7.1 \pm 0.6$ & $9.2 \pm 0.6$ & $9.4 \pm 0.8$ & $\mathrm{P}<0.001$ & $\mathrm{NS}$ \\
\hline Phosphorus (mg/dl) & $1.8 \pm 0.4$ & $5.00 \pm 0.6$ & $5.2 \pm 0.8$ & $\mathrm{P}<0.001$ & NS \\
\hline ALP (IU) & $490 \pm 50.2$ & $172 \pm 58.6$ & $155 \pm 42.6$ & $\mathrm{P}<0.001$ & NS \\
\hline iPTH (pg/ml) & $212.8 \pm 25.3$ & $47.5 \pm 7.2$ & $44.6 \pm 6.6$ & $\mathrm{P}<0.001$ & NS \\
\hline $\begin{array}{l}25(\mathrm{OH}) \text { vitamin } \mathrm{D} \\
(\mathrm{ng} / \mathrm{ml})\end{array}$ & $5.18 \pm 0.68$ & $23.9 \pm 2.34$ & $24.12 \pm 1.95$ & $\mathrm{P}<0.001$ & NS \\
\hline CRP (mg/l) & $14.01 \pm 1.73$ & $6.08 \pm 1.08$ & $5.65 \pm 1.12$ & $\mathrm{P}<0.001$ & NS \\
\hline IL-6 (ng/l) & $26.07 \pm 5.01$ & $6.64 \pm 1.27$ & $6.08 \pm 1.3$ & $\mathrm{P}<0.001$ & $\mathrm{NS}$ \\
\hline LVEDD (mm) & $31.92 \pm 1.04$ & $20.37 \pm 2.55$ & $21.1 \pm 2.1$ & $\mathrm{P}<0.001$ & NS \\
\hline LVESD (mm) & $23.57 \pm 1.15$ & $14.26 \pm 1.21$ & $13.98 \pm 1.5$ & $\mathrm{P}<0.001$ & NS \\
\hline $\mathrm{EF}(\%)$ & $57.41 \pm 3.43$ & $64.06 \pm 6.1$ & $66.5 \pm 8.6$ & $\mathrm{P}<0.001$ & NS \\
\hline FS (\%) & $23.96 \pm 0.99$ & $34.08 \pm 3.73$ & $35.9 \pm 3.9$ & $\mathrm{P}<0.001$ & NS \\
\hline IVSWT (mm) & $3.89 \pm 0.42$ & $3.96 \pm 0.45$ & $4.1 \pm 0.6$ & NS & NS \\
\hline LVPWT(mm) & $3.75 \pm 0.5$ & $3.8 \pm 0.82$ & $3.9 \pm 0.6$ & NS & NS \\
\hline $\mathrm{I} / \mathrm{L}$ & $1.06 \pm 0.06$ & $1.07 \pm 0.07$ & $1.05 \pm 0.04$ & NS & NS \\
\hline LVM (g) & $30.77 \pm 4.2$ & $31.65 \pm 3.4$ & $32 \pm 3.9$ & NS & NS \\
\hline $\operatorname{LVMI}\left(\mathrm{g} / \mathrm{m}^{2}\right)$ & $67.4 \pm 11.5$ & $65.43 \pm 11.7$ & $64.76 \pm 12.4$ & NS & $\mathrm{NS}$ \\
\hline $\mathrm{E} / \mathrm{A}$ & $1.33 \pm 0.05$ & $1.35 \pm 0.09$ & $1.34 \pm 0.07$ & NS & NS \\
\hline
\end{tabular}

Quantitative variables are expressed as mean $\pm \mathrm{SD}$, student $\mathrm{t}$ test were used to compare between the two groups. ALP: alkaline phosphatase; iPTH:intact parathyroid hormone; CRP: C-reactive protein; IL-6: interlukin-6; LVEDD: Left ventricular end diastolic diameter; LVESD: left ventricular end systolic diameter; FS: fractional shortening; EF: ejection fraction; IVSWT: interventricular septal wall thickness; LVPWT: left ventricular posterior wall thickness; I/L: interventricular posterior wall thickness / left ventricular posterior wall thickness; LVM: left ventricular mass; LVMI: left ventricular mass index; E/A ratio: $\mathrm{E}$ wave /A wave ratio. 


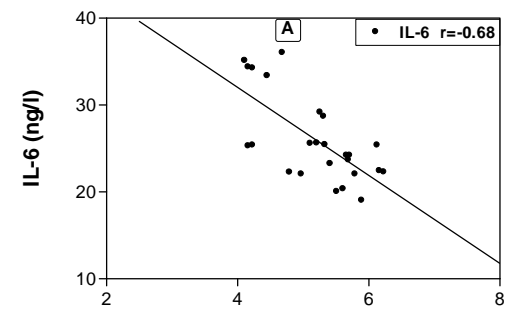

Vitamin-D level $(\mathrm{ng} / \mathrm{ml})$ at baseline

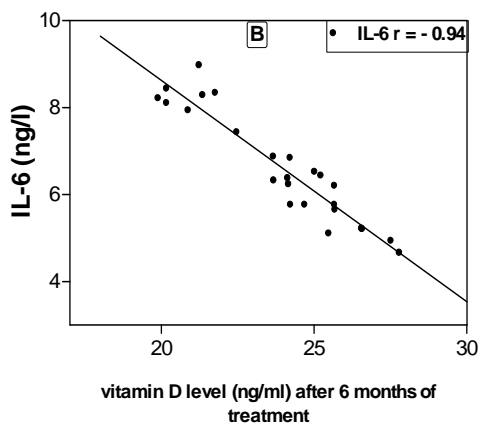

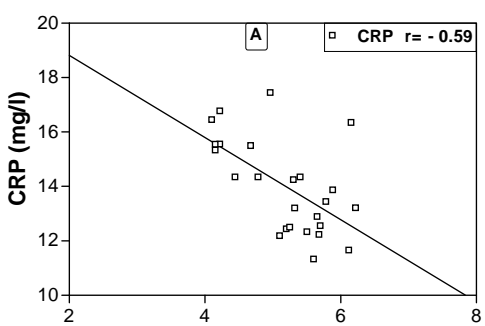

Vitamin-D level ( $\mathrm{ng} / \mathrm{ml})$ at baseline

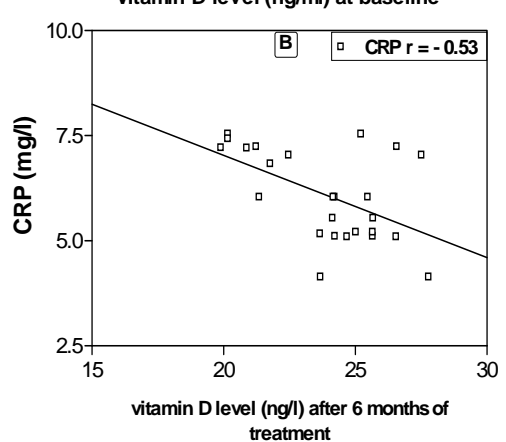

Figure 1: $A$ and $B$ correlation coefficients between Vitamin D and IL-6 and CRP in VDDR group at baseline (A) and after 6 months of treatment (B).
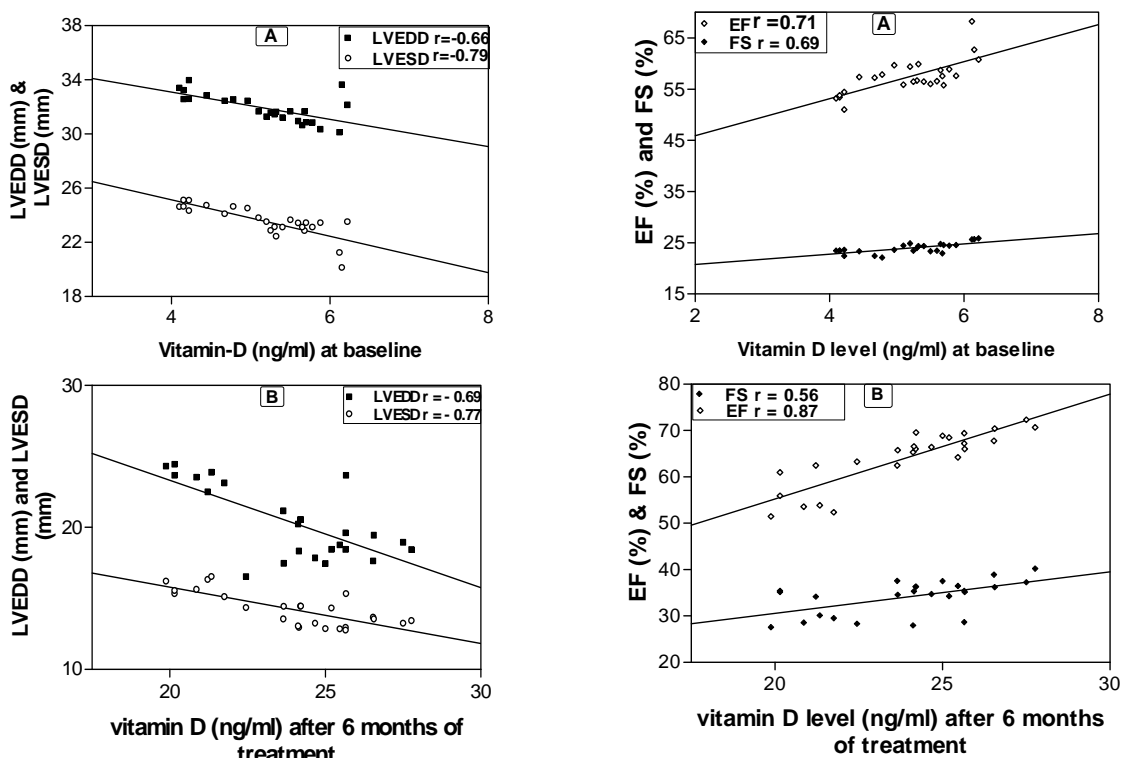

Figure 2: $A$ and $B$ correlation coefficients between Vitamin $D$ and each of echocardiographic parameters; LVEDD: Left ventricular end diasolic diameter; LVESD: left ventricular end systolic diameter; FS: fractional shortening; EF: ejection fraction in VDDR group at baseline (A) and after 6 months of treatment (B). 


\section{DISCUSSION}

Vitamin D has received worldwide attention not only for its importance for bone health in children and adults but also for reducing risk for many chronic diseases including autoimmune diseases, type 2 diabetes, heart disease, many cancers and infectious diseases ${ }^{(\mathbf{1 7})}$.

Vitamin D has net effect of increasing serum levels of calcium and phosphorus levels and achieves this by increasing intestinal calcium and phosphorus absorption. Vitamin $\mathrm{D}$ deficiency results in reduced serum calcium, which triggers secretion of parathyroid hormone to release calcium and phosphorus from bone in an attempt to maintain normal serum calcium levels ${ }^{(\mathbf{1 8})}$

Regarding the cardiovascular system, investigators have found an association between vitamin D deficiency and cardiovascular diseases and risk factors ${ }^{(19,20)}$.

Vitamin D reduces the expression of several genes which are upregulated in myocardial hypertrophy, e.g. by suppressing the cardiac rennin-angiotensin system and natriuretic peptides. Vitamin D has been shown to exert antihypertrophic effects on cardiomyocytes by increasing thrombomodulin and decreasing tissue factor ${ }^{(21)}$. Also, vitamin D exerts various effects on the growth and differentiation of cardiomyocytes, which are largely suggested to improve myocardial structure and function ${ }^{(21)}$. In addition, it has been shown that cardiac myocytes and fibroblasts express the enzymes $1 \alpha$-hydroxylase ${ }^{(\mathbf{2 2})}$.
Furthermore, the expression of myosin, a major contractile protein of the myocardium, is also regulated by vitamin $\mathrm{D}$ which may explain the associations of vitamin D status and myocardial contractility ${ }^{\mathbf{( 2 3 )}}$.

In the present study, serum $\mathrm{Ca}$ level was low in VDDR at baseline compared to the control group and reach to the normal level after 6 months of treatment with vitamin D. Within the heart, calcium ions are essential for the initiation of excitation-contraction coupling via an influx through L-type calcium channels. Once it is released from the sarcoplasmic reticulum by ryanodine receptors, calcium determines contractility by mediating the tension developed between actin and myosin filaments via the troponintropomyosin complex. Decreased amounts of available calcium lead to diminished responses in both of these areas and decreased cardiac function $^{(24)}$.

In the present work, PTH levels were high in VDDR group at baseline and decreased after 6 months of vitamin D treatment. As $25(\mathrm{OH})$ vitamin $\mathrm{D}$ falls, intestinal absorption of calcium falls leading to decreased serum calcium. This causes a rise in the serum PTH, which stimulate conversion of $25(\mathrm{OH}) \mathrm{D}$ to 1,25 $(\mathrm{OH}) 2 \mathrm{D}$ and thereby maintains absorption of calcium $^{(25)}$. Thus optimal level of $25(\mathrm{OH}) \mathrm{D}$ is defined as level which causes maximal suppression of PTH and maximum Calcium absorption ${ }^{(26)}$. Elevated PTH was level reported to be a cardiovascular risk factor independent of calcium and phosphorus levels ${ }^{(27)}$. 
PTH is pro-atherosclerotic, stimulates systemic and vascular inflammation, augmenting atherogenesis ${ }^{(28)}$. Also, high PTH levels activates the reninangiotensin system, causing increased blood pressure and left ventricular hypertrophy (with subsequent apoptosis and fibrosis) ${ }^{(\mathbf{1 9})}$. It is debated whether the beneficial effects of vitamin $\mathrm{D}$ on the cardiovascular system are direct or related to the physiological vitamin D-related lowering of PTH levels ${ }^{(29)}$.

Results of the present study showed a decrease in phosphorus level at baseline of VDDR group which improved after treatment. Liu et al. ${ }^{(30)}$ reported that hypophosphatemia caused left ventricular hypertrophy with upregulation of catecholamine and renin-angiotensin system components. Also, a previous study illustrated that the hypophosphatemia that resulted from vitamin D deficiency resulted in muscle weakness $^{(\mathbf{1 2})}$. They suggested that the muscle weakness could result from central importance of phosphorus in muscle function involving large amounts of ATP and the high level of phosphorylation and dephosphorylation of proteins during contraction and relaxation.

In our study, alkaline phosphatase (ALP) level was high at the study entry of the VDDR group which was normalized after 6 months of vitamin D supplementation. ALP is an excellent marker of rickets activity because it participate in the mineralization of bone and growth plate cartilage. Serum ALP is elevated in hypocalcemic rickets ${ }^{(31)}$. Sahay and Sahay ${ }^{(26)}$ suggested that ALP may be used for the screen of rickets.
In our study, serum IL-6 and CRP levels were elevated at the baseline and reached the normal levels after 6 months of vitamin D treatment. Alterations in the inflammatory markers with vitamin D deficiency were observed by many investigators $^{(32,34)}$. Thota et al. (34) showed that vitamin D caused down regulation of IL-6 and upregulation of anti-inflammatory cytokines. Also, Beilfuss et al. ${ }^{(35)}$ found that 1 year of vitamin D supplementation reduces the level of IL-6 in vitamin D deficient subjects. In addition, a study done on infants with congestive heart failure who have baseline 25hydroxyvitamin $\mathrm{D}$ below the lower end of the reference range, 12 weeks of vitamin D supplementation resulted in improvement of LVEDD, LVESD, $\mathrm{EF} \%, \mathrm{FS} \%$ and decreased IL-6 level ${ }^{(36)}$. He suggested that vitamin D is a potent anti-inflammatory agent that improved cytokine profile balance. Moreover, experimental evidences has been identified that vitamin D deficiency induced hypertrophy in cardiomyocytes with decreased expression of vitamin D receptor and suppressor of cytokine signaling (SOCS3) in cardiomyocyte which was also associated with increased inflammatory markers in epicardial adipose tissue ${ }^{(37)}$. Liss and Fisherman ${ }^{(38)}$ proposed that increment of proinflammatory cytokines tumor necrosis $-\alpha$ (TNF- $\alpha)$ and IL- 6 are one of the pathophysiological mechanisms involved in heart disease with vitamin D deficiency.

In the present study, EF\% and FS\% were lower while LVEDD and LVESD were higher in VDDR group at the baseline and normalized after 6 
months of treatment. $\mathrm{EF} \%$ and $\mathrm{FS} \%$ are the most commonly used parameters in the clinical evaluation of systolic functions of the left ventricle $^{(39)}$. This indicated the presence of systolic dysfunction and poor left ventricular contraction at baseline that reach normal values after treatment. Also, increased LVEDD and LVESD signified the presence of dilated left ventricle among the studied subjects. The combination of dilated left ventricle and poor contractility of left ventricle implying dilated cardiomyopathy among VDDR subjects. Verma et al. (9) reported that VDDR caused asymptomatic left ventricular dysfunction that improves with treatment. They concluded that VDDR must the considered as an important curable cause for dilated cardiomyopathy among children especially in regions where nutritional rickets is still common.

Finally, our results demonstrated significant -ve correlations in VDDR group between Vitamin D and each of IL-6, CRP levels, LVESD and LVEDD at baseline and after 6 months of treatment. On the other hand, significant +ve correlations were observed between vitamin $\mathrm{D}$ and $\mathrm{FS} \%$ and $\mathrm{EF} \%$. These results are in line with Eleftheriadis et al. ${ }^{(40)}$ who found inverse correlation between Vitamin D and IL-6 and CRP and Fall et al. ${ }^{(41)}$ who observed higher circulating vitamin $\mathrm{D}$ concentrations to be associated with better left ventricular systolic function and smaller LVESD. This means that the increment of vitamin D concentration in VDDR is associated with improvement of cytokines profile and left ventricular function.

In conclusion, Vitamin D deficiency in rachitic infants is associated with increment of inflammatory markers and left ventricular impairment. Vitamin D supplementation in rickets reduces the cardiovascular complication and improves the associated systemic inflammation. Also, our results support the concept of a possible contributing role of the elevated inflammatory markers in the pathophysiology of impaired left ventricular function in vitamin $D$ deficient rachitic infants.

\section{REFERENCES}

1- Thacher T, Fischer P, Strand M, Pettifor J. (2006) Nutritional rickets around the world: causes and future directions. Ann. Trop. Paediatr., 26:1-16.

2- Baroncelli GI, Bereket A, EI Kholy M, Audì L, Cesur Y, Ozkan B, Rashad M, Fernández-Cancio $M$, Weisman Y, Saggese G, Hochberg $Z$. (2008): Rickets in the Middle East: role of environment and genetic predisposition. J. Clin. Endocrinol. Metab., 93:17431750 .

3- Muscogiuri G, Sorice GP, Ajjan R, Mezza T, Pilz S, Prioletta A, Scragg R, Volpe SL, Witham MD, Giaccari A. (2012): Can vitamin $\mathrm{D}$ deficiency cause diabetes and cardiovascular diseases? Present evidence and future perspectives. Nutr. Metab. Cardiovasc. Dis., 22:81-87. 
4- Pilz S, Tomaschitz A, Drechsler C, Dekker JM, März W. (2010): Vitamin D deficiency and myocardial diseases. Mol Nutr. Food Res., 54:1103-1113.

5- Chen S, Law CS, Grigsby CL, Olsen K, Hong TT, Zhang Y, Yeghiazarians Y, Gardner DG. (2011): Cardiomyocyte-specific deletion of the vitamin $\mathrm{D}$ receptor gene results in cardiac hypertrophy. Circulation 124:1838-1847.

6- Nibbelink KA, Tishkoff DX, Hershey SD, Rahman A, Simpson RU. (2007): 1,25(OH)2-vitamin D3 actions on cell proliferation, size, gene expression, and receptor localization, in the HL-1 cardiac myocyte. J. Steroid Biochem. Mol. Biol., 103:533-537.

7- Wu J, Garami M, Cheng T, Gardner DG. (1996): 1,25(OH)2 vitamin D3, and retinoic acid antagonize endothelin-stimulated hypertrophy of neonatal rat cardiac myocytes. J. Clin. Invest., 97:1577-1588.

8- Lee W and Kang PM. (2010): Vitamin D deficiency and cardiovascular disease: is there a role for vitamin D therapy in heart failure? Curr. Opin. Investig. Drugs 11: 309-314.

9- Verma S, Khadwal A, Chopra K, Rohit M, Singhi S. (2011): Hypocalcemia nutritional rickets: a curable cause of dilated cardiomyopathy. J. Trop. Pediatr., 57:126-128.

10- May E, Asadullah K, Zugel U. (2004): Immunoregulation through 1,25- dihydroxyvitamin D3 and its analogs. Curr. Drug
Targets Inflamm Allergy 3: 377393.

11- Canning MO, Grotenhuis K, de Wit H, Ruwhof C, Drexhage HA. (2001): 1-alpha, 25Dihydroxyvitamin D3 $(1,25(\mathrm{OH})(2) \mathrm{D}(3))$ hampers the maturation of fully active immature dendritic cells from monocytes. Eur. J. Endocrinol., 145:351-357.

12- Schubert $L$ and DeLuca HF. (2010): Hypophosphatemia is responsible for skeletal muscle weakness of vitamin D deficiency. Arch. Biochem. Biophys., 15:157-161.

13- Kudo K, Hasegawa S, Suzuki Y, Hirano R, Wakiguchi $\mathbf{H}$, Kittaka S, Ichiyama T. (2012): $1 \alpha, 25$-Dihydroxyvitamin $\mathrm{D}(3)$ inhibits vascular cellular adhesion molecule-1 expression and interleukin-8 production in human coronary arterial endothelial cells. J. Steroid Biochem. Mol. Biol., 132:290294.

14- Hatun S, Ozkan Z, Orbak, Doneray H, Cizmecioglu F, Toprak D and Calikoglu A. (2005): Vitamin D deficiency in early infancy. J. Nutr., 135: 279282.

15- Park MK. (2008): Chest roentgenography,

electrocardiography and non invasive techniques. In: pediatric cardiology for practitioners; $\mathrm{P}$ 40, P-66, P-81.

16- Brunvand $L$, Haga $P$, Tangsrud SE, Haug E. (1995): Congestive heart failure caused by vitamin D deficiency? Acta Pediatr., 84:106108. 
17- Holick MF. (2012): Evidencebased D-bate on health benefits of vitamin D revisited. Dermatoendocrinol., 1:183-190.

18- Fauci A, Braunwald E, Isselacherk,et al. (1998): Harrison's principle of internal medicine, $4^{\text {th }}$ ed, New York, NW; Mc Grew Hill

19- Mertens PR and Müller $R$. (2010): Vitamin $\mathrm{D}$ and cardiovascular risk. Int. Urol. Nephrol., 42:165-171.

20- Annuzzi G, Della Pepa G, Vetrani C. (2012): Vitamin D and cardiovascular disease: is there evidence to support the bandwagon? Curr. Atheroscler. Rep., 14:525-534.

21- Lindqvist PG, Epstein E, Olsson H. (2009): Does an active sun exposure habit lower the risk of venous trombotic events? A Dlightful hypothesis. J. Thromb. Haemost., 7:605-610.

22- Chen S, Glenn DJ, Ni W, Grigsby $\mathbf{C L}$ Olsen $\mathbf{K}$, Nishimoto M, Law CS, Gardner DG. (2008): Expression of the vitamin D receptor is increased in the hypertrophic heart. Hypertension 52: 11061112.

23- Wang G F, Nikovits Jr W, Bao Z Z, Stockdale FE. (2001): Irx4 forms an inhibitory complex with the vitamin $\mathrm{D}$ and retinoic $\mathrm{X}$ receptors to regulate cardiac chamber-specific slow MyHC3 expression. J. Biol. Chem., 276: 28835-28841.

24- Opie L. (2001): Mechanisms of cardiac contraction and relaxation. In: Braunwald $\mathrm{E}$ (ed) Heart disease, 6th ed. W. B.
Saunders, Philadelphia, pp 443478.

25- Durazo-Arvizu RA, DawsonHugeh B, Sempos CT, Yetley EA, Looker AC, Cao G, Harris SS, Burt VL, Carriquiry AL, Picciano MF. (2010): Three phase model harmonizes estimates of the maximal suppression of parathyroid hormone by 25 hydroxy vitamin $\mathrm{D}$ in persons 65 years of age and older. J. Nutr., 140: 595- 599.

26- Sahay $M$ and Sahay R. (2012): Rickets- Vitamin D deficiency and dependency. Indian j. Endocrinol. Metab., 16:164-176.

27- Lishmanov A, Dorairajan S, Pak Y, Chaudhary K, Chockalingam A. (2012): Elevated serum parathyroid hormone is a cardiovascular risk factor in moderate chronic kidney disease. Int. Urol. Nephrol., 44:541-547.

28- Ameri P, Ronco D, Casu M, Denegri A, Bovio M, Menoni S, Ferone D, Murialdo G. (2010): High prevalence of vitamin D deficiency and its association with left ventricular dilation: an echocardiography study in elderly patients with chronic heart failure. Nutr. Metab. Cardiovasc. Dis., 20:633-640.

29- Qayyum F, Landex NL, Agner BR, Rasmussen M, Jøns C, Dixen U. (2012): Vitamin D deficiency is unrelated to type of atrial fibrillation and its complications. Dan. Med. J., 59: A4505.

30- Liu P, Bai X, Wang H, Karaplis A, Goltzman D, Miao D. (2009): Hypophosphatemia-mediated 
hypotension in transgenic mice overexpressing human FGF-23 Am. J. Physiol. Heart Circ. Physiol., 297: H1514-H1520.

31- Whyte MP. (2010): Physiological role of alkaline phosphatase explored in hypophosphatasia. Ann. NY Acad. Sci., 1192:190-200.

32- Jamali Z, Arababadi MK, Asadikaram G. (2012): Serum levels of IL-6, IL-10, IL-12, IL17 and IFN- $\gamma$ and their association with markers of bone metabolism in vitamin Ddeficient female students. Inflammation 36(1): 164-166..

33- van de Luijtgaarden KM, Voûte MT, Hoeks SE, Bakker EJ, Chonchol M, Stolker RJ, Rouwet EV, Verhagen HJ. (2012): Vitamin D deficiency may be an independent risk factor for arterial disease. Eur. J. Vasc. Endovasc. Surg., 44:301-306.

34- Thota C, Farmer T, Garfield RE, Menon R, Al-Hendy A. (2012): Vitamin D elicits antiInflammatory response, inhibits contractile-associated proteins, and modulates toll-like receptors in human myometrial cells. Reprod. Sci., doi: 10.1177/1933719112459225.

35- Beilfuss J, Berg V, Sneve M, Jorde R, Kamycheva E. (2012): Effects of a 1-year supplementation with cholecalciferol on interleukin-6, tumor necrosis factor-alpha and insulin resistance in overweight and obese subjects. Cytokine 60:870-874.
36- Shedeed SA. (2012): Vitamin D supplementation in infants with chronic congestive heart failure. Pediatr. Cardiol., 33:713-719.

37- Gupta GK, Agrawal T, DelCore MG, Mohiuddin SM, Agrawal DK. (2012): Vitamin D deficiency induces cardiac hypertrophy and inflammation in epicardial adipose tissue in hypercholesterolemic swine. Exp. Mol. Pathol., 93: 82-90.

38- Liss $Y$ and Frishman WH. (2012): Vitamin D: A Cardioprotective Agent? Cardiol. Rev., 20: 38-44.

39- Ocall B, Unal S, Zorlu P, Tezic HT, Oğuz D et al. (2001): Echocardiographic evaluation of cardiac functions and left ventricular mass in children with malnutrition J. Paediatr. Child Health 37: 14-17.

40- Eleftheriadis T, Antoniadi G, Liakopoulos V, Stefanidis I, Galaktidou G. (2012): Inverse association of serum 25Hydroxyvitamin D with markers of inflammation and suppression of osteoclastic activity in hemodialysis patients. Iran. J. Kidney Dis., 6:129-135.

41- Fall T, Shiue I, Bergeå Af Geijerstam P, Sundström J, Arnlöv J, Larsson A, Melhus H, Lind L, Ingelsson E. (2012): Relations of circulating vitamin D concentrations with left ventricular geometry and function. Eur. J. Heart Fail., 14: 985-991. 


\section{تأثير نقص فيتامين د على دلالات الالتهابات ووظائف البطين الأيسر عند الرضع المصابين بالكساح}

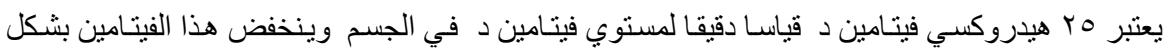

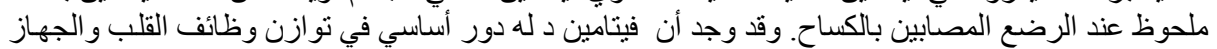

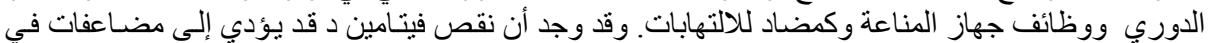
القلب و الجهاز الدوري و عدم التوازن في مستويات دلايلات الالتهاب التهاب.

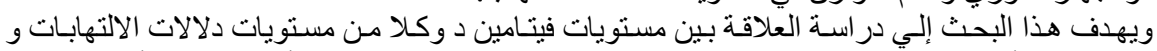

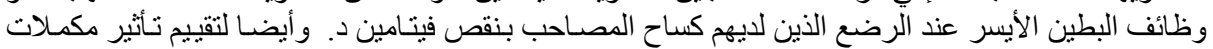
فيتامين د على المعايير السابقة. وقا شملت هذه الاراسة مجموعتين:

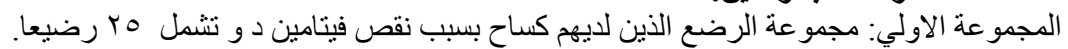

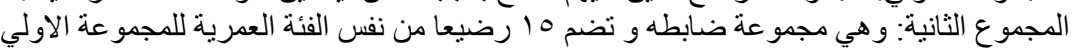

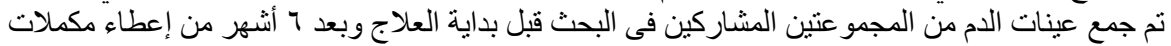

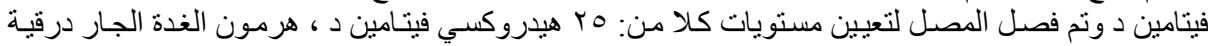

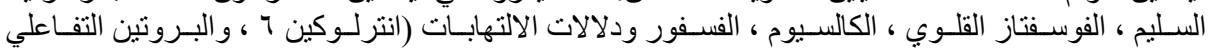

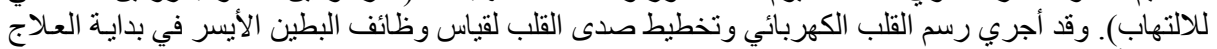
وبعد 1 أنشهر من إعطاء مكملات فيتامين د.

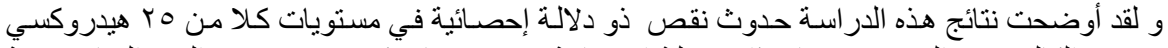

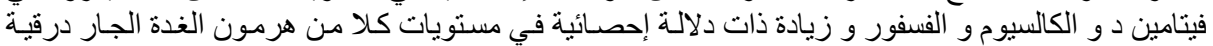

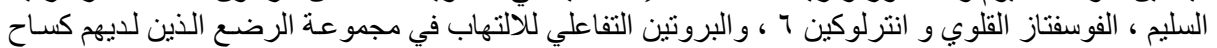

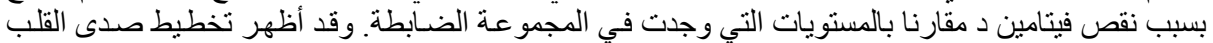

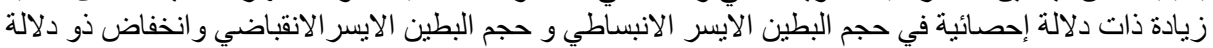

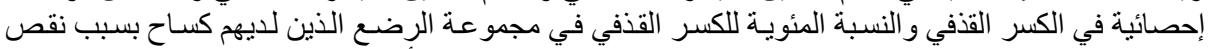

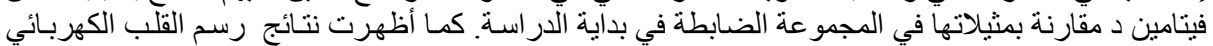

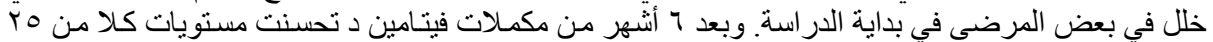

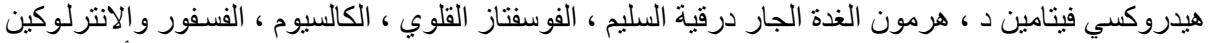

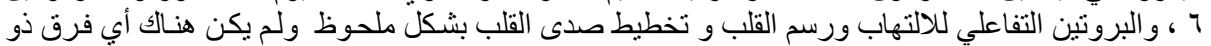

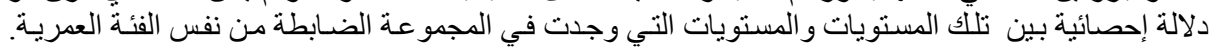

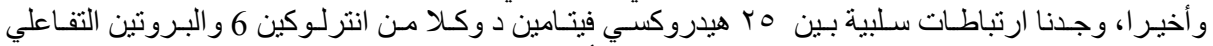

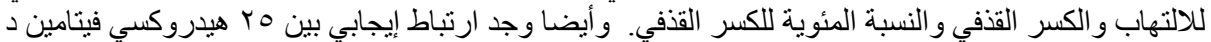

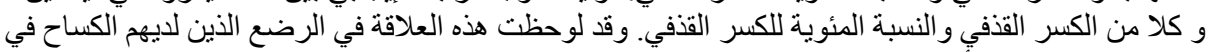

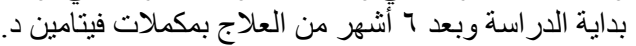

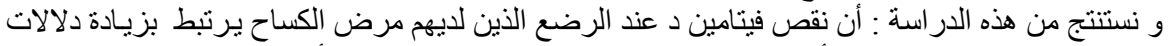

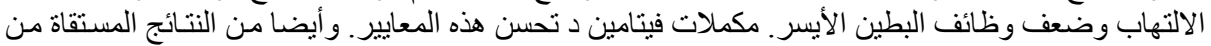

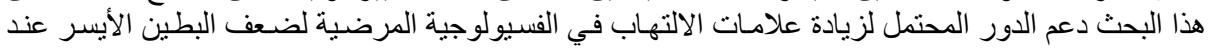

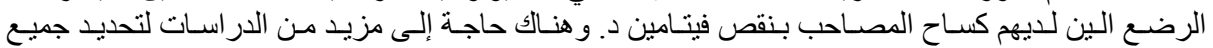

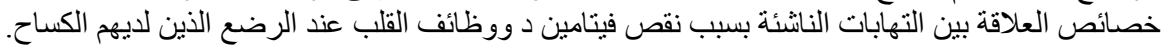

